\title{
On the assessment of U-shaped notches using Failure Assessment Diagrams and the Line Method: experimental overview and validation
}

\author{
S. Cicero ${ }^{1 *}$, V. Madrazo ${ }^{2}$, T. García ${ }^{1}$
}

1) Dpto. Ciencia e Ingeniería del Terreno y de los Materiales, Universidad de Cantabria, Av/ Los Castros 44, 39005, Santander, Cantabria, Spain

2) Fundación Centro Tecnológico de Componentes (CTC), Parque Científico y Tecnológico de Cantabria (PCTCAN), C/ Isabel Torres n 1, 39011, Santander, Spain

*corresponding author: ciceros@ unican.es

\begin{abstract}
This paper analyses the structural integrity of components containing U-shaped notches by combining Failure Assessment Diagrams and the Line Method correction for notch effects. With this objective, the experimental results obtained in 555 fracture tests are homogeneously evaluated in the same Failure Assessment Diagram, with and without applying the Line Method notch corrections, and covering a wide range of materials such as PMMA, Al7075-T651, four different structural steels (S275JR, S355J2, S460M and S690Q) tested at different temperatures from the lower shelf up to the ductile-tobrittle transition zone, and two rocks (granite and limestone). It is demonstrated that the proposed methodology generally produces significant reductions in the conservatism associated to notch effects, yet providing safe predictions.
\end{abstract}

Keywords: Failure Assessment Diagram, Line Method, Theory of Critical Distances, apparent fracture toughness, notch effect

\section{Introduction}

The structural integrity assessment of components containing cracks may be addressed using the Failure Assessment Diagram (FAD) methodology, which allows a simultaneous assessment against fracture, plastic collapse and their corresponding 
interaction. However, the integrity assessment (and the load-bearing capacity predictions) of structural components containing notches using the same methodology leads to generally overconservative results, given that the fracture resistance developed by a given material in notched conditions may be much higher than that developed in cracked conditions (e.g., [1-8]). Notches (and stress risers, in general) can take very different forms. This paper is focused on U-shaped notches, which may appear in structural components due to design details, mechanical damage, corrosion defects or fabrication defects, among others $[9,10]$.

The authors have published a number of papers analysing the notch effect in different materials (e.g., $[3-5,11,12]$ ), and have also provided a model for the structural integrity assessment of notches by using the FAD methodology and the Line Method (LM) correction for the consideration of notch effects $[13,14]$. This model has been validated individually for different materials (e.g., PMMA and A17075-T651 [13], and structural steels S275JR and S355J2 [14]), but the results are not directly comparable, given that the Failure Assessment Line (FAL) defining the critical situation in the corresponding FAD depends on the material tensile properties, so that the FAL used in the above mentioned research varies with the material being analysed.

The aim of this paper is to extend the validation of the proposed methodology for the structural integrity of U-shaped notches, by including a wider scope of materials (those mentioned above plus structural steels S460M and S690Q, and two rocks limestone and granite-) and also by providing a homogenous analysis of all of them, that is, analysing all the different materials and experimental results in the same FAD. The tests cover very different conditions (different materials, notch radii, testing specimens, testing temperatures, parameter calibration processes, etc.), summing 555 structural integrity assessments and providing a general validation of the methodology. 
With all this, Section 2 presents some theoretical background about FADs and the LM, Section 3 describes the materials being analysed and the assessment model (materials and methods), Section 4 provides the results and the corresponding discussion and, finally, Section 5 gathers the main conclusions.

\section{Theoretical background: Failure Assessment Diagrams and the Line Method}

\subsection{Failure Assessment Diagrams}

Failure Assessment Diagrams (FADs) constitute one of the main engineering tools for the assessment of fracture-plastic collapse processes in cracked components. As explained in [15], they were first introduced by Dowling and Townley [16] and Harrison et al. [17], and were derived from the modified version of the strip yield model [18,19] proposed by Burdekin and Stone [20]. In the last decades, they have been introduced in the most important structural integrity assessment procedures (e.g., [2124]), led by the R6 procedure [23].

For a given structural component containing a crack, FADs present a simultaneous assessment of both fracture and plastic collapse processes by using two normalised parameters, $\mathrm{K}_{\mathrm{r}}$ and $\mathrm{L}_{\mathrm{r}}$, whose expressions are:

$$
\begin{aligned}
& K_{r}=\frac{K_{I}}{K_{m a t}} \\
& L_{r}=\frac{P}{P_{L}}
\end{aligned}
$$

$\mathrm{P}$ being the applied load, $\mathrm{P}_{\mathrm{L}}$ being the limit load, $\mathrm{K}_{\mathrm{I}}$ being the stress intensity factor, and $\mathrm{K}_{\mathrm{mat}}$ being the material fracture resistance measured by the stress intensity factor (e.g., $\mathrm{K}_{\mathrm{IC}}, \mathrm{K}_{\mathrm{Jc}}$, etc). $\mathrm{L}_{\mathrm{r}}$ may also be expressed following equation (3), which is totally equivalent to equation (2) [22]: 


$$
L_{r}=\frac{\sigma_{r e f}}{\sigma_{Y}}
$$

$\sigma_{\text {ref }}$ being the reference stress, obtained by multiplying equation (2) by the yield stress, and $\sigma_{Y}$ being the material yield stress.

$\mathrm{L}_{\mathrm{r}}$ evaluates the structural component situation against plastic collapse, and $\mathrm{K}_{\mathrm{r}}$ evaluates the component against fracture, the assessed component being represented by a point of coordinates $\left(\mathrm{K}_{\mathrm{r}}, \mathrm{L}_{\mathrm{r}}\right)$. Once the component assessment point is defined through these coordinates, it is necessary to define the component limiting conditions (i.e., those leading to final failure). To this end, the Failure Assessment Line (FAL) is defined, so that if the assessment point is located between the FAL and the coordinate axes, the component is considered to be under safe conditions, whereas if the assessment point is located above the FAL, the component is considered to be under unsafe conditions. The critical situation (failure condition) is that in which the assessment point lies exactly on the FAL. Figure 1 shows an example with the three different possible situations when performing fracture initiation analyses.

In any case, the FAL follows expressions which are functions of $\mathrm{L}_{\mathrm{r}}$ :

$$
K_{r}=f\left(L_{r}\right)
$$

From an engineering point of view, and beyond the origins of the FAD based on the strip yield model, the $f\left(L_{r}\right)$ functions are actually plasticity corrections to the linearelastic fracture assessment $\left(\mathrm{K}_{\mathrm{I}}=\mathrm{K}_{\mathrm{mat}}\right)$, whose exact analytical solution is:

$$
f\left(L_{r}\right)=\sqrt{\frac{J_{e}}{J}}
$$

$\mathrm{J}$ being the applied $\mathrm{J}$-integral and $\mathrm{J}_{\mathrm{e}}$ being its corresponding elastic component [15].

The analysis is limited by the cut-off, which corresponds to the load level causing the plastic collapse of the analysed component. This cut-off is defined by the maximum 
value of $L_{r}$ (see $L_{r}{ }^{m a x}$ in Figure 1), which depends on the material flow stress (usually the average value of the yield stress and the ultimate tensile strength).

In practice, structural integrity assessment procedures (e.g., [21-24]) provide approximate solutions to equation (5), which are defined through the tensile properties of the material. These approximate solutions are generally provided hierarchically, that is, defining different levels on which the more defined the material stress-strain curve, the more approximate are such solutions to equation (5). For instance, [21] defines an Option 0 (Basic) FAL, which does not require any tensile data, whereas Option 1 (Standard) requires both the yield or proof strength and the ultimate tensile strength, and Option 3 is defined through the full stress-strain curve (Option 2 in [21] is dedicated to a mismatch analysis). As an example, Option 0 for those materials which display or may be expected to display a yield plateau (discontinuous yielding), is defined by the following equations:

$$
\begin{array}{ll}
f\left(L_{r}\right)=\left[1+0.5\left(L_{r}\right)^{2}\right]^{-1 / 2} & \mathrm{~L}_{\mathrm{r}} \leq 1 \\
f\left(L_{r}\right)=0 & \mathrm{~L}_{\mathrm{r}}>1
\end{array}
$$

Thus, the FAL used in Option 0 does not depend on the material tensile properties and it is material independent. This has consequences in the structural integrity assessments, in terms of higher conservatism and lower accuracy of the results [21-24].

The position of the assessment point provides information about the predominant failure mechanism (see Figure 1). Following FITNET FFS [21], failures represented by assessment points above the $\mathrm{K}_{\mathrm{r}} / \mathrm{L}_{\mathrm{r}}=1.1$ line are fracture dominated, whereas failures represented by points located below the $\mathrm{K}_{\mathrm{r}} / \mathrm{L}_{\mathrm{r}}=0.4$ line are plastic collapse dominated. In intermediate situations $\left(0.4<\mathrm{K}_{\mathrm{r}} / \mathrm{L}_{\mathrm{r}}<1.1\right)$ fracture and plastic collapse are competing failure mechanisms. 
From an engineering point of view, a key point in the FAD methodology is that the fracture analysis is based on a linear-elastic parameter $\left(\mathrm{K}_{\mathrm{I}}\right)$, regardless of the plasticity level existing on the crack tip. Moreover, together with the equations defining the FAL, structural integrity assessment procedures provide $\mathrm{K}_{\mathrm{I}}$ and $\mathrm{P}_{\mathrm{L}}$ solutions for a wide variety of components (plates, pipes, spheres...) and crack geometries (surface cracks, through thickness crack, corner crack...), something that facilitates the development of structural integrity assessments.

\subsection{The Line Method}

The Line Method (LM) is one of the approaches included within the Theory of the Critical Distances (TCD), which comprises a group of methodologies with a common aspect: they all use a characteristic material length parameter (the critical distance) when performing fracture assessments [8]. The origins of the TCD are located in the middle of the twentieth century $[25,26]$, but in the last two decades this theory has had a wider development, providing answers to different scientific and engineering problems (e.g., $[4,5,8,11,27-34])$.

The above-mentioned length parameter is generally referred to as the critical distance, $\mathrm{L}$, and in fracture analyses it follows the equation [11]:

$$
L=\frac{1}{\pi}\left(\frac{K_{m a t}}{\sigma_{0}}\right)^{2}
$$

where $\mathrm{K}_{\mathrm{mat}}$ is the material fracture toughness obtained for cracked specimens, and $\sigma_{0}$ is the inherent strength (a characteristic material strength parameter) which is usually larger than the ultimate tensile strength $\left(\sigma_{\mathrm{u}}\right)$ and must be calibrated. $\sigma_{0}$ coincides with $\sigma_{\mathrm{u}}$ in those situations where there is a linear-elastic behaviour at both the micro and the macro scales (e.g., fracture of ceramics and certain rocks). 
There are different methodologies, within the TCD, allowing fracture analyses to be performed [8], such as the Point Method (PM), the Line Method (LM), the Imaginary Crack Method (ICM) and Finite Fracture Mechanics (FFM). In any case, the evaluations made by these methodologies are very similar [8], and both the PM and the LM are particularly simple. Therefore, for the sake of simplicity, this theoretical overview is focused on the LM.

The LM assumes that fracture occurs when the average stress along a certain distance, $2 \mathrm{~L}$, reaches the inherent strength, $\sigma_{0}$ [25, 35-37]. Therefore, the LM expression is:

$$
\frac{1}{2 L} \int_{0}^{2 L} \sigma(r) d r=\sigma_{0}
$$

Other authors have presented formally similar approaches, with the distance $2 \mathrm{~L}$ referred to as the "effective distance", which determines the fracture process zone and is defined by the minimum of the relative gradient of the opening stress around the notch [38,39], and the inherent stress (or effective stress) defined as the average value of the stress distribution inside the fracture process zone [38,39].

Moreover, the LM (and also the PM) provides expressions for the apparent fracture toughness $\left(\mathrm{K}^{\mathrm{N}}\right.$ mat $)$ exhibited by notched components. In the case of U-shaped notches (as those analysed in this paper) the LM may be applied considering the linear-elastic stress distribution at the notch tip provided by Creager and Paris [40], which is equal to that ahead of the crack tip but displaced a distance equal to $\rho / 2$ along the $x$-axis, the latter being located in the notch midplane and having its origin at the crack tip [40] :

$$
\sigma(r)=\frac{K_{I}}{\sqrt{\pi}} \frac{2(r+\rho)}{(2 r+\rho)^{3 / 2}}
$$


where $K_{I}$ is the stress intensity factor for a crack with the same size as the notch, $\rho$ is the notch radius and $\mathrm{r}$ is the distance from the notch tip to the point being assessed. Equation (10) was derived for long thin notches (i.e., notch depth $>>$ notch radius) and is only valid for small distances from the notch tip ( $\mathrm{r}<<$ notch depth).

If the LM is applied, Equation (9) may be combined with Equation (10), giving [8]:

$$
K_{m a t}^{N}=K_{m a t} \sqrt{1+\frac{\rho}{4 L}}
$$

This relation reduces the fracture analysis of a notched component to an equivalent situation of a cracked component, with the only particularity of considering $\mathrm{K}^{\mathrm{N}}$ mat instead of $\mathrm{K}_{\mathrm{mat}}$. Thus, fracture occurs when:

$$
K_{I}=K_{m a t}^{N}
$$

Analogously, the authors have demonstrated [4,28] that notches may be analysed by using Failure Assessment Diagrams and substituting $\mathrm{K}_{\text {mat }}$ with $\mathrm{K}^{\mathrm{N}}$ mat in the definition of the $\mathrm{K}_{\mathrm{r}}$ coordinate of the assessment point, which is defined as the ratio between the applied stress intensity factor $\left(\mathrm{K}_{\mathrm{I}}\right)$ and the material fracture resistance $\left(\mathrm{K}_{\text {mat }}\right.$ for cracks and $\mathrm{K}^{\mathrm{N}}$ mat for notches) [29-31].

The authors have recently provided [41] a wide validation of the LM, demonstrating the accuracy of its apparent fracture toughness predictions through its homogenous application to 555 experimental results. From an engineering (and scientific) point of view, the next step consists in using such apparent fracture toughness predictions to perform structural integrity assessments, given that fracture is not the only failure mechanism and, thus, equation (12) would not be sufficient in many practical situations (those where plastic collapse is the main failure mechanism and 
those where the failure is a consequence of the interaction between fracture and plastic collapse). Thus, the structural integrity of the same 555 experimental results mentioned above will be used here to validate the methodology proposed by the authors to analyse the structural integrity assessment of notched components through the combination of FADs and the LM.

\section{Materials and methods}

\subsection{Materials}

The authors have recently published several papers showing the application of the LM to a wide variety of materials and conditions. Polymethyl methacrylate (PMMA) is analysed in [4], aluminium alloy A17075-T651 with two different orientations (LT and TL) is analysed in [5], the analysis of two common rocks (granite and oolitic limestone) is gathered in [11], and four structural steels (S275JR, S355J2, S460M and S690Q) are analysed in $[3,12]$. Moreover, the four steels have been tested at 3 different temperatures within their corresponding Ductile-to-Brittle Transition Zone (DBTZ) and, in the case of steels S275JR and S355J2, at temperatures within their Lower Shelf. The resultant experimental programme comprises 20 different mechanical behaviours, as shown in Table 1 . The total number of tests is 555 , with fracture toughness values $\left(\mathrm{K}_{\text {mat }}\right)$ ranging from $0.72 \mathrm{MPa} \cdot \mathrm{m}^{1 / 2}$ up to $157.4 \mathrm{MPa} \cdot \mathrm{m}^{1 / 2}$, and critical distance values (L) varying from $0.0028 \mathrm{~mm}$ up to $6.04 \mathrm{~mm}$. Some materials presented pure brittle behaviour (e.g., $\mathrm{S} 275 \mathrm{JR}$ at $-120^{\circ} \mathrm{C}, \mathrm{S} 355 \mathrm{~J} 2$ at $-196^{\circ} \mathrm{C}$, granite and limestone), whereas other materials presented ductile behaviour before the onset of cleavage fracture (e.g., the four steels at the different temperatures belonging to their corresponding DBTZ).

The fracture toughness tests $\left(\mathrm{K}_{\text {mat }}\right)$ and the apparent fracture toughness tests $\left(\mathrm{K}^{\mathrm{N}}{ }_{\text {mat }}\right)$ were performed following well-known standards [42,43] or procedures [44]. PMMA 
and steels S460M and 690Q were tested by using SENB (3 point bending) specimens [4,12], Al7075-T651 and steels S275JR and S355J2 were tested by using CT specimens $[3,5]$, and the two rocks (granite and limestone) were tested by using SENB (4 point bending) specimens [11]. Concerning the calibration of the material critical distance (L), three different methodologies were followed (revealing the versatility of the TCD): PMMA and Al7075-T651 were calibrated by using the Finite Element method (FE) (ANSYS 12.1) and the PM (the notch tip stress fields of two specimens with different notch radii cross each other at a distance from the notch tip equal to $L / 2$ [8]). Following the literature (e.g., [8]), the simulations were conducted in purely linear-elastic conditions, despite the non-linear phenomena that may occur in PMMA and A17075T651. Also, the mesh was performed using hexahedric elements (SOLID186), the mesh being much more refined at the defect tip, because of the higher gradients appearing in this zone; the granite and the limestone were calibrated by the direct application of equation (8), and assuming that the inherent strength, $\sigma_{0}$, is equal to the ultimate tensile strength, $\sigma_{\mathrm{u}}$; finally, the $\mathrm{L}$ value of the four steels at the different temperatures was calibrated by a least squares fitting of the experimental results.

Consequently, the experimental results collected here represent an extensive range of situations, and any validation derived from them would provide confidence about the methodology being analysed.

\subsection{Methods}

The notch assessment methodology analysed here combines the LM with the FAD methodology $[13,14]$, introducing a notch correction in the $\mathrm{K}_{\mathrm{r}}$ parameter. The definition of this parameter in notch analysis would be: 


$$
K_{r}=\frac{K_{I}}{K_{m a t}^{N}}=\frac{K_{I}}{K_{\text {mat }} \sqrt{1+\frac{\rho}{4 L}}}
$$

Therefore, equation (13) substitutes equation (1) when the defects being analysed are U-shaped notches, instead of cracks. Analogous expressions could be derived for other notch geometries (e.g., V-notches), provided the corresponding stress fields are used to derive equations (11) and (13).

The FAD analysis also needs to define the $\mathrm{L}_{\mathrm{r}}$ parameter, which depends on the limit load (equation (2)). Plastic collapse occurs through the yielding of the remanent section, so that in a perfectly plastic material, it can be defined by the material yield stress and the defect dimensions, with no influence of the radius existing on the defect tip. In [45] the low influence of the notch radius on the limit load is demonstrated.

Finally, the last question to be defined to complete the FAD analysis is the FAL. Horn and Sherry have demonstrated a weak dependence of the R6 Option 3 failure assessment curves on the notch radius $[46,47]$.

With all this, it can be concluded that, from an engineering point of view, the methodology analysed here for the assessment of notch-type defects converts a notched material with $\mathrm{K}_{\text {mat }}$ as the fracture resistance into an equivalent situation with a cracked material having a higher fracture resistance $\left(\mathrm{K}^{\mathrm{N}}\right.$ mat $)[13,14]$. This conversion just requires the $\mathrm{K}_{\mathrm{r}}$ parameter to be modified, using the same $\mathrm{L}_{\mathrm{r}}$ and $\mathrm{FAL}$ solutions defined for the assessment of crack-like defects. If this methodology is compared to the assessment of notches as if they were cracks (a conservative practice), equation (13) produces a reduction of the $\mathrm{K}_{\mathrm{r}}$ parameter and, consequently, a vertical displacement 
(downwards) of the assessment point [13,14]. Alternative FAD approaches applied to notch type defects have been proposed in (for example) $[38,48,49]$.

In order to have a homogeneous representation of the 555 experimental results, it is necessary to use a FAL that does not depend on the tensile properties of the material being analysed. Thus, the FAL defined by FITNET FFS Option 0 (discontinuous yielding) [21] will be used here. The corresponding equations have been gathered above (equations (6) and (7)). This FITNET FFS Option 0 is a conservative version of BS7910 Option 1 [22].

\section{Results and discussion}

Figure 2 shows FAD assessment at failure of the 555 tests when notches are treated as if they were cracks, that is, following equations (1) and (2). Here, it should be noted that following common engineering practice, the value of $\mathrm{K}_{\text {mat }}$ considered for each material has been that one providing a 95\% confidence level $\left(\mathrm{K}_{\text {mat } 0.95}\right.$, see Table 1$)$, which, assuming a normal distribution is equal to the mean value obtained in cracked conditions minus 1.645 times the corresponding standard deviation. Thus, the strict expression of the $\mathrm{K}_{\mathrm{r}}$ parameter when notches are treated as cracks is:

$$
K_{r}=\frac{K_{I}}{K_{\text {mat } 0.95}}
$$

It can be observed that the assessment points, which correspond to the failure of the different specimens, are generally far away from the theoretical failure conditions, which are defined by the FAL. This means that the failure load predictions derived from the FAD analysis would have been much lower than the actual ones. This circumstance is more pronounced when the notch radius increases (i.e., the higher the notch radius the more distant the assessment point from the FAL). If the FAD conservatism Factor of Failure (CFF) is defined as shown in Figure 1, the conservatism factors obtained in 
Figure 2 are close to 5 on many occasions (corresponding to the specimens with larger notch radii). Moreover, regardless of the specific CFF obtained in each specimen, the average value observed in Figure 1 is around 2.5. This reveals a high degree of (over)conservatism when treating notches as if they were cracks [50,51], and justifies the need for more accurate structural integrity assessment methodologies for notch-type defects.

Figure 3 represents the FAD assessment of the 555 experimental results when applying the methodology here analysed and, thus, when the notch correction provided by the $\mathrm{LM}$ is included in the FAD. The expression used for $\mathrm{K}_{\mathrm{r}}$ is:

$$
K_{r}=\frac{K_{I}}{K_{\text {mat } 0.95} \sqrt{1+\frac{\rho}{4 L}}}
$$

On this occasion, a great reduction in the conservatism can be observed. The highest values of the CFF are below 3.0, with an average value around 1.3. Thus, the methodology proposed here provides much more accurate predictions of the failure conditions in notched specimens than those provided by the crack-like assessments. It can also be observed that there are 14 assessment points located in the safe area (between the FAL and the coordinate axes). These points correspond to unsafe failure predictions of the model, which represent $2.5 \%$ of all the assessments and constitute a reasonable number of predictions if it is considered that the fracture toughness values used in the analyses have been those corresponding to a $95 \%$ confidence level (the probability of failure being 5\%). 7 of the 14 unsafe predictions correspond to structural steel S690Q tested at $-140^{\circ} \mathrm{C}$ in the ductile-to-brittle transition zone, and this kind of overestimations of the notch effect may appear when the scatter in the apparent fracture toughness results is elevated. Figure 4 [12] shows the corresponding $\mathrm{K}^{\mathrm{N}}$ mat results, revealing the mentioned scatter and its significance: if the $\mathrm{L}$ value is obtained through 
the best fit curve, the $\mathrm{K}^{\mathrm{N}}$ mat predictions (provided by the fitting curve) may be much higher than the experimental results. This may have direct consequences in the FAD assessments, generating unsafe predictions, and could be avoided (for example) by using the $\mathrm{L}$ value associated to the lower envelope curve of the $\mathrm{K}^{\mathrm{N}}$ mat results [12].

With the aim of reducing the number of unsafe predictions when applying the notch correction in the FAD, the lower bound expression of the LM proposed in [41] will be used here. Equations (16) and (17) gather the notch correction and the corresponding $\mathrm{K}_{\mathrm{r}}$ correction, respectively. The " 0.73 " factor intends to capture the scatter observed in the fracture toughness results obtained in cracked conditions [41], intending to provide a 95\% confidence level of the whole population of tests. This factor, together with the "20" factor inside the square root provide a lower estimate of the apparent fracture toughness results of the 555 tests used here.

$$
\begin{gathered}
K_{\text {mat }}^{N}=0.73 \cdot K_{\text {mat }} \sqrt{1+\frac{\rho}{20 L}} \\
K_{r}=\frac{K_{I}}{0.73 \cdot K_{\text {mat }} \sqrt{1+\frac{\rho}{20 L}}}
\end{gathered}
$$

Here, it should be noted that the $K_{\text {mat }}$ value used in equations (16) and (17) corresponds to the mean value obtained for each material, and not to $\mathrm{K}_{\text {mat0.95 }}$.

Figure 5 shows the results obtained when applying equation (17). It can be observed how the notch correction still provides significant reductions in the conservatism, with maximum values of the CFF around 3.0 and an average value of approximately 1.6. Thus, the results obtained when using this correction are less accurate than those obtained when using equation (15). In contrast, the number of unsafe predictions is reduced to $3(0.5 \%)$. 
Finally, another contribution of the methodology (regardless of the equation being used, (15) or (17)) is that it provides a more precise prediction of the actual failure mechanisms (e.g., $[3,12,13,52])$. Many of the assessment points obtained when notches are treated as cracks are associated to high values of $\mathrm{K}_{\mathrm{r}}$ within the FAD. This implies high $\mathrm{K}_{\mathrm{r}} / \mathrm{L}_{\mathrm{r}}$ ratios (see Figure 2) and, therefore, the analysis would predict fracture (or fracture-plastic collapse) dominated failures. Nevertheless, the observation of the corresponding fracture surfaces usually reveals more ductile (e.g., plastic collapse dominated) failure mechanisms, as a result of a much higher material fracture resistance than that considered in the assessment (e.g., $[3,12,13,52]$ ). Thus, the $\mathrm{K}_{\mathrm{r}} / \mathrm{L}_{\mathrm{r}}$ ratios of 0.4 and 1.1 mentioned above cannot be taken as a reference when assessing notch-type defects as if they were cracks. However, after the application of the notch effect correction in the $\mathrm{FAD}$, and the resultant reduction of $\mathrm{K}_{\mathrm{r}}$, the assessment points satisfy the relation between the $\mathrm{K}_{\mathrm{r}} / \mathrm{L}_{\mathrm{r}}$ ratios of 0.4 and 1.1 and the corresponding failure mechanisms $[3,12,13,52]$, as explained above for the case of crack-like defects. As an example, the arrow in figures 2,3 and 5 correspond to a CT specimen containing a notch with a $2.0 \mathrm{~mm}$ radius, made of steel S275JR and tested at $-90^{\circ} \mathrm{C}$ : a crack like assessment predicts a fracture dominated failure, with no influence of plastic collapse, whereas the application of the LM corrections predicts that ductile mechanisms are involved in the final failure. Figure 6 shows the actual failure mechanism, revealing the development of ductile mechanisms prior to final failure.

\section{Conclusions}

This paper validates a structural integrity assessment methodology for U-shaped notches which is based on the use of Failure Assessment Diagrams (FAD) and the notch effect corrections provided by the Line Method (LM). When compared to the FAD analysis of crack-like defects, the methodology limits the notch effect corrections to the 
definition of the $\mathrm{K}_{\mathrm{r}}$ parameter (fracture analysis), keeping unaltered the definition of the $\mathrm{L}_{\mathrm{r}}$ parameter (plastic collapse analysis) and the Failure Assessment Line (FAL). Two notch corrections have been used: that one derived from the strict application of the LM together with the $95 \%$ confidence level fracture toughness, and the lower bound notch correction derived from an experimentally fitted version of the LM, which uses the mean value of the fracture toughness obtained in cracked conditions.

The methodology has been validated by using 555 experimental results that cover a wide variety of materials (PMMA, A17075-T651, granite, limestone, and four structural steels - S275JR, S355J2, S460M and S690Q - at different temperatures from their lower shelf up to their corresponding ductile-to-brittle transition zone). The results show that the failure predictions when applying the proposed notch assessment methodology are much closer to the FAL than those obtained when notches are treated as crack-like defects. Thus, the accuracy of the predictions is noticeably increased and the overconservatism is significantly reduced, with a reasonable and reduced number of cases providing unsafe results regardless of which one of the two LM notch effect corrections is used.

\section{Acknowledgement}

The authors of this work would like to express their gratitude to the Spanish Ministry of Economy and Competitiveness for the financial support of the projects MAT201015721: 'Análisis de integridad estructural en defectos tipo entalla' and MAT201458443: "Análisis del comportamiento en fractura de components estructurales con defectos en condiciones de bajo confinamiento tensional", on the results of which this paper is based.

\section{REFERENCES}


[1] F. Berto, P. Lazzarin, Recent developments in brittle and quasi-brittle failure assessment of engineering materials by means of local approaches, Mat. Sci. Eng. R. 75 (2014) 1-48.

[2] F.J.Gómez, M. Elices, Fracture loads for ceramic samples with rounded notches, Eng. Fract. Mech. 73 (2006) 880-894.

[3] S. Cicero, V. Madrazo, T. García, Analysis of notch effect in the apparent fracture toughness and the fracture micromechanisms of ferritic-pearlitic steels operating within their lower shelf, Eng. Fail. Anal. 36 (2014) 322-342.

[4] S. Cicero, V. Madrazo, I.A. Carrascal, Analysis of notch effect in PMMA by using the Theory of Critical Distances, Eng. Fract. Mech. 86 (2012) 56-72.

[5] V. Madrazo, S. Cicero, I.A. Carrascal, On the point method and the line method notch effect predictions in A17075-T651, Eng. Fract. Mech. 79 (2012) 363-379.

[6] L.S. Niu, C. Chehimi, G. Pluvinage, Stress field near a large blunted V notch and application of the concept of notch stress intensity factor to the fracture of very brittle materials, Eng. Fract. Mech. 49 (1994) 325-335.

[7] G. Pluvinage, Fatigue and fracture emanating from notch; the use of the notch stress intensity factor, Nucl. Eng. Des. 185 (1998) 173-184.

[8] D. Taylor, The theory of critical distances: a new perspective in fracture mechanics, Elsevier, UK, 2007.

[9] M. Allouti, S. Jallouf, C. Schmitt, G. Pluvinage, Comparison between hot surface stress and effective stress acting at notch-like defect tip in a pressure vessel, Eng. Fail. Anal. 18 (2011) 846-854.

[10] M. Allouti, C. Schmitt, G. Pluvinage, Assessment of a gouge and dent defect in a pipeline by a combined criterion, Eng. Fail. Anal. 36 (2014) 1-13.

[11] S. Cicero, T. García, J. Castro, V. Madrazo, D. Andrés, Analysis of notch effect on the fracture behaviour of granite and limestone: An approach from the Theory of Critical Distances, Eng. Geol. 177 (2014) 1-9.

[12] S. Cicero, T. García, V. Madrazo, Application and validation of the Notch Master Curve in medium and high strength structural steels, J. Mech. Sci. Tech. (2015) Accepted for publication, In press.

[13] S. Cicero, V. Madrazo, I.A. Carrascal, R. Cicero, Assessment of notched structural components using failure assessment diagrams and the theory of critical distances, Eng. Fract. Mech. 78 (2011) 2809-2825.

[14] V. Madrazo, S. Cicero, T. García, Assessment of notched structural steel components using failure assessment diagrams and the theory of critical distances, Eng. Fail. Anal. 36 (2014) 104-120. 
[15] T.L. Anderson, Fracture mechanics: fundamentals and applications, CRC Press, Florida, USA, 2005.

[16] A.R. Dowling, C.H.A. Townley, The effects of defects on structural failure: a two criteria approach, Int. J. Pres.Ves. Pip. 3 (1975) 77-137.

[17] R.P. Harrison, K. Loosemore, I. Milne, Assessment of the integrity of structures containing defects, CEGB Report R/H/R6, Central Electricity Generating Board, UK, 1976.

[18] D.S. Dugdale, Yielding in steel sheets containing slits, J. Mech. Phys. Solids. 8, (1960) 100-104.

[19] G.I. Barenblatt, The mathematical theory of equilibrium cracks in brittle fracture, Adv. App. Mech. VII (1962) 55-129.

[20] F.M. Burdekin, D.E.W. Stone, The crack opening displacement approach to fracture mechanics in yielding materials, J. Strain Anal. 1 (1966) 145-153.

[21] FITNET Fitness-for-Service (FFS) Proceure - Volume 1, M. Kocak, S. Webster, J.J. Janosch, R.A. Ainsworth, R. Koers, eds., ISBN 978-3-940923-00-4, Printed by GKSS, Germany, 2008.

[22] BS 7910: 2013, Guide to methods for assessing the acceptability of flaws in metallic structures, British Standards Institution, London, UK, 2013.

[23] R6: Assessment of the integrity of structures containing defects, British Energy Generation Limited, Revision 4, Gloucester, UK, 2001.

[24] API 579-1/ASME FFS-1 Fitness-For-Service, American Society of Mechanical Engineers, New York, USA, 2007.

[25] H. Neuber, Theory of notch stresses: principles for exact calculation of strength with reference to structural form and material, Springer Verlag, Berlin, 1958.

[26] R.E. Peterson, Notch sensitivity, in: G. Sines, J.L. Waisman (Eds.), Metal fatigue., McGraw Hill, 1959, pp. 293-306.

[27] L. Susmel, D. Taylor, Fatigue design in the presence of stress concentrations, J. Strain Anal. Eng. Des. 38 (2003) 443-452.

[28] L. Susmel, D. Taylor, On the use of the Theory of Critical Distances to predict failures in ductile metallic materials containing different geometrical features, Eng. Fract. Mech. 75 (2008) 4410-4421.

[29] L. Susmel, D. Taylor, D., An elasto-plastic reformulation of the Theory of Critical Distances to estimate lifetime of notched components failing in the low/medium-cycle fatigue regime, J. Eng. Mater. Technol. 132 (2010) 021002132. 
[30] D. Taylor, A mechanistic approach to critical-distance methods in notch fatigue, Fatig. Fract. Eng. Mater. Struct. 24 (2001) 215-224.

[31] D. Taylor, G. Wang, The validation of some methods of notch fatigue analysis, Fatig. Fract. Eng. Mater. Struct. 23 (2000) 387-394.

[32] D. Taylor, P. Bologna, K. Bel Knani, Prediction of fatigue failure location on a component using a critical distance method, Int. J. Fatig. 22 (2000) 735-742.

[33] A. Carpinteri, A. Spagnoli, S. Vantadori, D. Viappiani, A multiaxial criterion for notch high-cycle fatigue using a critical-point method, Eng. Fract. Mech. 75 (2008) 1864-1874.

[34] A. Carpinteri, C. Ronchei, A. Spagnoli, S. Vantadori, Lifetime estimation in the low/medium-cycle regime using the Carpinteri-Spagnoli multiaxial fatigue criterion, Theor. Appl. Fract. Mech. 73 (2014) 120-127.

[35] J.M. Whitney, R.J. Nuismer, Stress fracture criteria for laminated composites containing stress concentrations, J. Compos. Mater. 8 (1974) 253-265.

[36] V.V. Novozhilov, On a necessary and sufficient criterion for brittle strength, Prik. Mat. Mek. 33 (1969) 201-210.

[37] A. Seweryn, Brittle fracture criterion for structures with sharp notches, Eng. Fract. Mech. 47 (1994) 673-681.

[38] R.Adib, S. Jallouf, C. Schmitt, A. Carmasol, G.Pluvinage, Evaluation of the effect of corrosion defects on the structural integrity of X52 gas pipelines using the SINTAP procedure and notch theory, Int. J. Pres. Ves. Pip. 84 (2007) 123-131.

[39] C. Schmitt, G. Pluvinage, E. Hadj-Taieb ,R. Akid, Water pipeline failure due to water hammer effect, Fatig. Fract. Eng. Mater. Struct. 29 (2006) 1075-108.

[40] M. Creager, C. Paris, Elastic field equations for blunt cracks with reference to stress corrosion cracking, Int. J. Fract. 3 (1967) 247-252.

[41] S. Cicero, T. García, V. Madrazo, On the Line Method apparent fracture toughness evaluations: experimental overview, validation and some consequences on fracture assessments, Theor. Appl. Fract. Mech. (2015) In press.

[42] ASTM D5045-99, Standard Test Methods for Plane-Strain Fracture Toughness and Strain Energy Release Rate of Plastic Materials. American Society of Testing and Materials, Philadelphia, 1999.

[43] ASTM E1820-09e1, Standard test method for measurement of fracture toughness. American Society for Testing and Materials, Philadelphia, 2009. 
[44] CEN/TS 14425-1:2003, Advanced technical ceramics-test methods for determination of fracture toughness of monolithic ceramics-part 1: guide to test method selection. European Committee for Normalization, 2003.

[45] A.G. Miller, Review of limit loads of structures containing defects, Int. J. Pres. Ves. Pip. 32 (1988) 197-327.

[46] A.J. Horn, A.H. Sherry, An engineering assessment methodology for non-sharp defects in steel structures - Part I: Procedure development, Int. J. Pres. Ves. Pip. 89 (2012) 137-150.

[47] A.J. Horn, A.H. Sherry, An engineering assessment methodology for non-sharp defects in steel structures - Part II: Procedure validation and constraint analysis, Int. J. Pres. Ves. Pip. 89 (2012) 151-161.

[48] M.A. Bouaziz, M.A. Guidara, C. Schmitt, E. Hadj-Taïeb, Z. Azari, Water hammer effects on a gray cast iron water network after adding pumps, Eng. Fail. Anal. 44 (2014) $1-16$.

[49] M. Allouti, C. Schmitt, G. Pluvinage, Assessment of a gouge and dent defect in a pipeline by a combined criterion, Eng. Fail. Anal. 36 (2014) 1-13.

[50] K. Rouabeh, C. Schmitt, S. Elaoud, E. Hadj-Taïeb, G. Pluvinage, Failure of grey cast iron water pipe due to resonance phenomenon, Eng. Fail. Anal. 26 (2012) 120-128.

[51] S. Jallouf, C. Schmitt, G. Pluvinage, E. Hadj-Taieb, M.Lebienvenu, Probabilistic safety factor for defect assessment of water pipes subjected to water hammer, J. Strain Anal. Eng. Des. 46 (2011) 14-26.

[52] S. Cicero, F. Gutiérrez-Solana, J.A. Álvarez, Structural integrity assessment of components subjected to low constraint conditions, Eng. Fract. Mech. 75 (2008) 30383059 . 


\section{NOMENCLATURE}

$\mathrm{J}$

$\mathrm{J}_{\mathrm{e}} \quad$ elastic component of $\mathrm{J}$

$\mathrm{K}_{\mathrm{mat}}$

$\mathrm{K}_{\text {mat0 } 0.95}$

$\mathrm{K}^{\mathrm{N}}$ mat

$\mathrm{K}_{\mathrm{I}}$

$\mathrm{K}_{\mathrm{r}}$

$\mathrm{L}$

$\mathrm{L}_{\mathrm{r}}$

$r$

$\rho$

$\sigma$

$\sigma_{\text {ref }}$

$\sigma_{\mathrm{u}}$

$\sigma_{\mathrm{Y}}$

$\sigma_{0}$

$\mathrm{CFF}$

applied J-integral

stress intensity factor

notch radius

applied stress

reference stress

yield stress material fracture toughness (mean value)

material fracture toughness associatee to a $95 \%$ confidence level

apparent fracture toughness

fracture ratio of applied $\mathrm{K}_{\mathrm{I}}$ to fracture resistance (e.g., $\mathrm{K}_{\mathrm{mat}}, \mathrm{K}^{\mathrm{N}}{ }_{\text {mat }} \ldots$ )

material critical distance

ratio of applied load to limit load

distance from the notch tip

ultimate tensile strength

material strength parameter (the inherent strength)

Conservatism Factor of Failure 
DBTZ Ductile-to-Brittle Transition Zone

FAD Failure Assessment Diagram

FAL Failure Assessment Line

FE

Finite Element method

LM Line Method

LS Lower Shelf

PM Point Method

TCD Theory of Critical Distances 


\section{Tables}

Table 1. Summary of the experimental results analysed in this paper (LS: Lower Shelf; DBTZ: Ductile-to-Brittle Transition Zone; FE: Finite Element method). Kmat refers to the mean value obtained in cracked conditions; $\mathrm{K}_{\text {mat } 0.95}$ refers to the $95 \%$ confidence level in cracked conditions.

\begin{tabular}{|c|c|c|c|c|c|c|}
\hline Material & $\begin{array}{c}\text { Number } \\
\text { of tests }\end{array}$ & $\begin{array}{c}\text { Notch } \\
\text { radii } \\
(\mathbf{m m})\end{array}$ & $\begin{array}{c}\mathbf{K}_{\mathrm{mat}} \\
\left(\mathbf{M P a} \cdot \mathbf{m}^{1 / 2}\right)\end{array}$ & $\begin{array}{c}\mathrm{K}_{\text {mat } 0.95} \\
\left(\mathbf{M P a} \cdot \mathbf{m}^{\mathbf{1} / 2}\right)\end{array}$ & $\begin{array}{c}\mathbf{L} \\
(\mathbf{m m})\end{array}$ & $\begin{array}{l}\text { Calibration } \\
\text { method (L) }\end{array}$ \\
\hline PMMA & 32 & $0-2.5$ & 2.04 & 1.54 & 0.1050 & FE \\
\hline Al7075-T651 LT & 23 & $0-2.0$ & 27.01 & 24.34 & 0.0150 & FE \\
\hline Al7075-T651 TL & 24 & $0-2.0$ & 26.65 & 24.23 & 0.0215 & FE \\
\hline Granite & 41 & $0-10$ & 1.24 & 1.08 & 6.04 & Eq. (1) \\
\hline Limestone & 41 & $0-10$ & 0.72 & 0.68 & 2.71 & Eq. (1) \\
\hline $\begin{array}{l}\text { S275JR } \\
\left(-120^{\circ} \mathrm{C}, \mathrm{LS}\right)\end{array}$ & 23 & $0-2.0$ & 48.80 & 34.40 & 0.0137 & Best fit \\
\hline $\begin{array}{l}\text { S275JR } \\
\left(-90^{\circ} \mathrm{C}, \mathrm{LS}\right)\end{array}$ & 24 & $0-2.0$ & 62.72 & 60.30 & 0.0062 & Best fit \\
\hline $\begin{array}{l}\text { S275JR } \\
\left(-50^{\circ} \mathrm{C}, \text { DBTZ }\right)\end{array}$ & 24 & $0-2.0$ & 80.60 & 59.81 & 0.0049 & Best fit \\
\hline $\begin{array}{l}\text { S275JR } \\
\left(-30^{\circ} \mathrm{C}, \text { DBTZ) }\right.\end{array}$ & 24 & $0-2.0$ & 100.7 & 79.02 & 0.0061 & Best fit \\
\hline $\begin{array}{l}\text { S275JR } \\
\left(-10^{\circ} \mathrm{C}, \mathrm{DBTZ}\right)\end{array}$ & 34 & $0-2.0$ & 122.8 & 90.22 & 0.0083 & Best fit \\
\hline $\begin{array}{l}\mathrm{S} 355 \mathrm{~J} 2 \\
\left(-196^{\circ} \mathrm{C}, \mathrm{LS}\right)\end{array}$ & 24 & $0-2.0$ & 31.27 & 27.41 & 0.0198 & Best fit \\
\hline $\begin{array}{l}\text { S355J2 } \\
\left(-150^{\circ} \mathrm{C}, \text { DBTZ }\right)\end{array}$ & 21 & $0-2.0$ & 60.56 & 40.30 & 0.0084 & Best fit \\
\hline $\begin{array}{l}\mathrm{S} 355 \mathrm{~J} 2 \\
\left(-120^{\circ} \mathrm{C}, \mathrm{DBTZ}\right)\end{array}$ & 22 & $0-2.0$ & 146.6 & 120.4 & 0.0168 & Best fit \\
\hline $\begin{array}{l}\text { S355J2 } \\
\left(-100^{\circ} \mathrm{C}, \text { DBTZ }\right)\end{array}$ & 35 & $0-2.0$ & 157.4 & 107.7 & 0.0140 & Best fit \\
\hline $\begin{array}{l}\text { S460M } \\
\left(-140^{\circ} \mathrm{C}, \mathrm{DBTZ}\right)\end{array}$ & 24 & $0-2.0$ & 45.60 & 32.67 & 0.0028 & Best fit \\
\hline $\begin{array}{l}\mathrm{S} 460 \mathrm{M} \\
\left(-120^{\circ} \mathrm{C}, \mathrm{DBTZ}\right)\end{array}$ & 24 & $0-2.0$ & 88.29 & 36.42 & 0.0075 & Best fit \\
\hline $\begin{array}{l}\text { S460M } \\
\left(-100^{\circ} \mathrm{C}, \mathrm{DBTZ}\right)\end{array}$ & 33 & $0-2.0$ & 88.58 & 60.73 & 0.0053 & Best fit \\
\hline $\begin{array}{l}\text { S690Q } \\
\left(-140^{\circ} \mathrm{C}, \mathrm{DBTZ}\right)\end{array}$ & 24 & $0-2.0$ & 69.11 & 52.54 & 0.0069 & Best fit \\
\hline $\begin{array}{l}\text { S690Q } \\
\left(-120^{\circ} \mathrm{C}, \mathrm{DBTZ}\right)\end{array}$ & 24 & $0-2.0$ & 103.8 & 61.37 & 0.0131 & Best fit \\
\hline $\begin{array}{l}\text { S690Q } \\
\left(-100^{\circ} \mathrm{C}, \mathrm{DBTZ}\right)\end{array}$ & 34 & $0-2.0$ & 125.4 & 53.68 & 0.0170 & Best fit \\
\hline
\end{tabular}




\section{Figures}

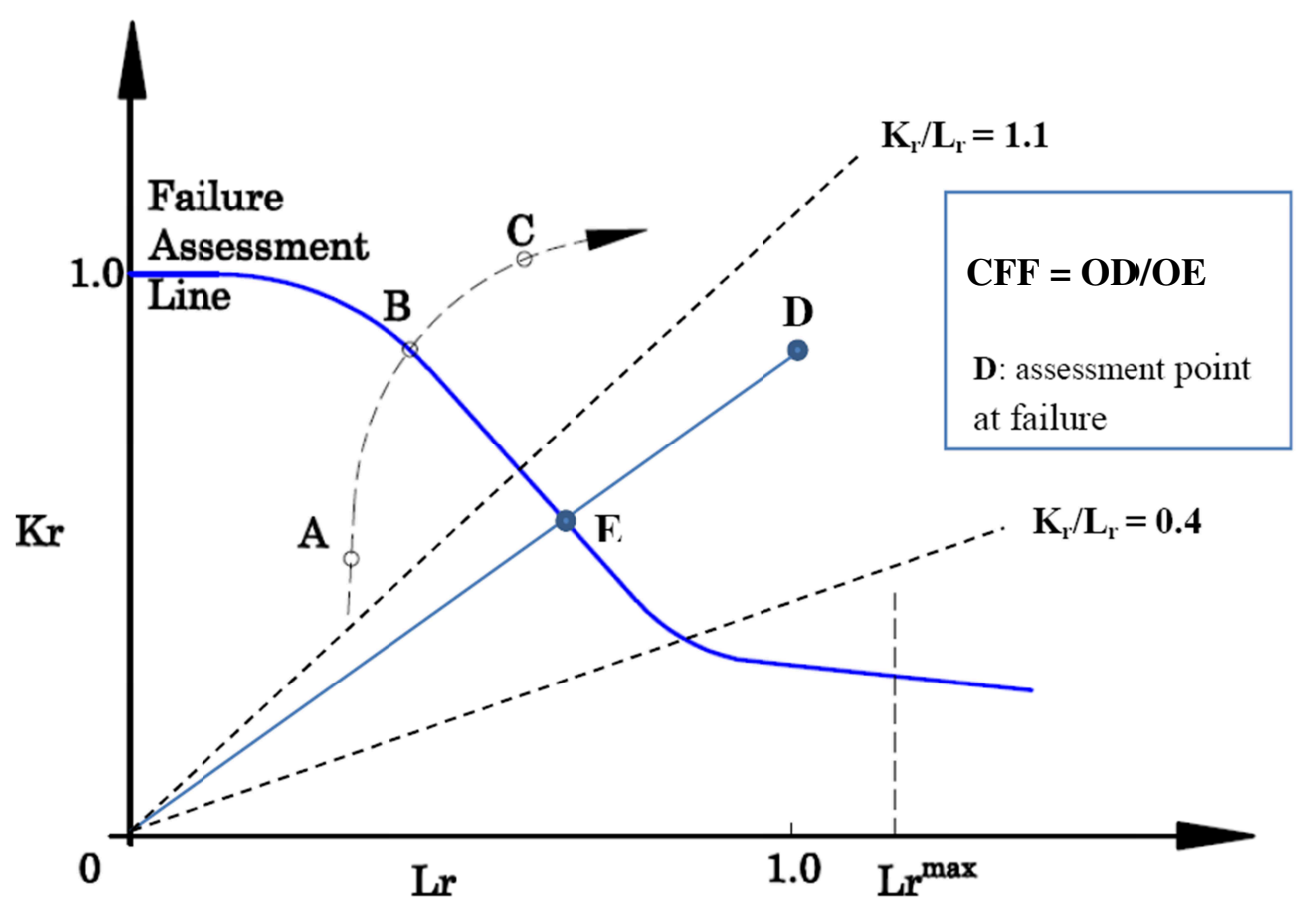

Figure 1. FAD analysis showing three possible situations: A, safe conditions; B, critical condition; $\mathrm{C}$, unsafe conditions. 


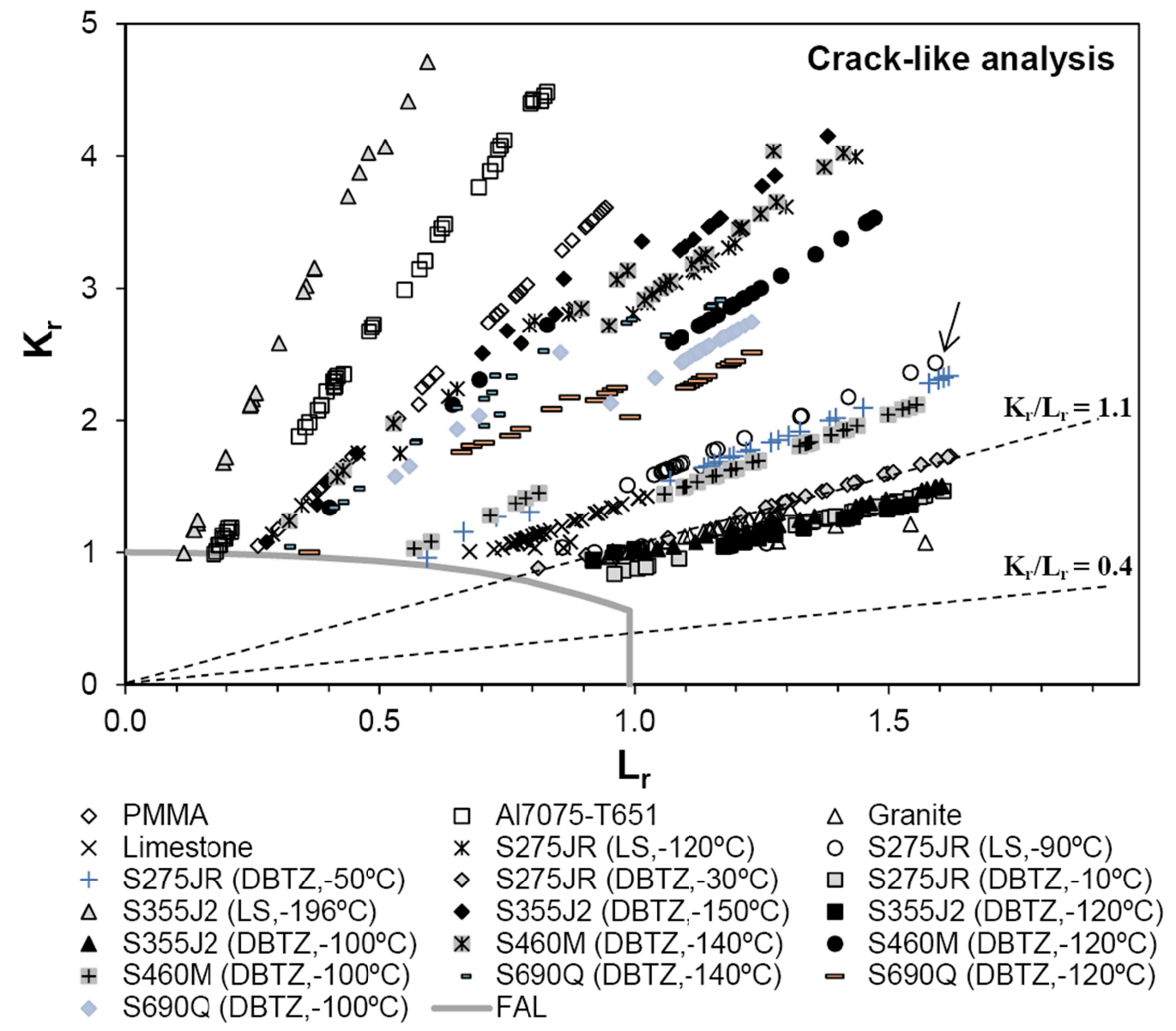

Figure 2. FAD analysis of the 555 experimental results. Notches are analysed as if they were cracks (without any notch correction, equation (14)). 


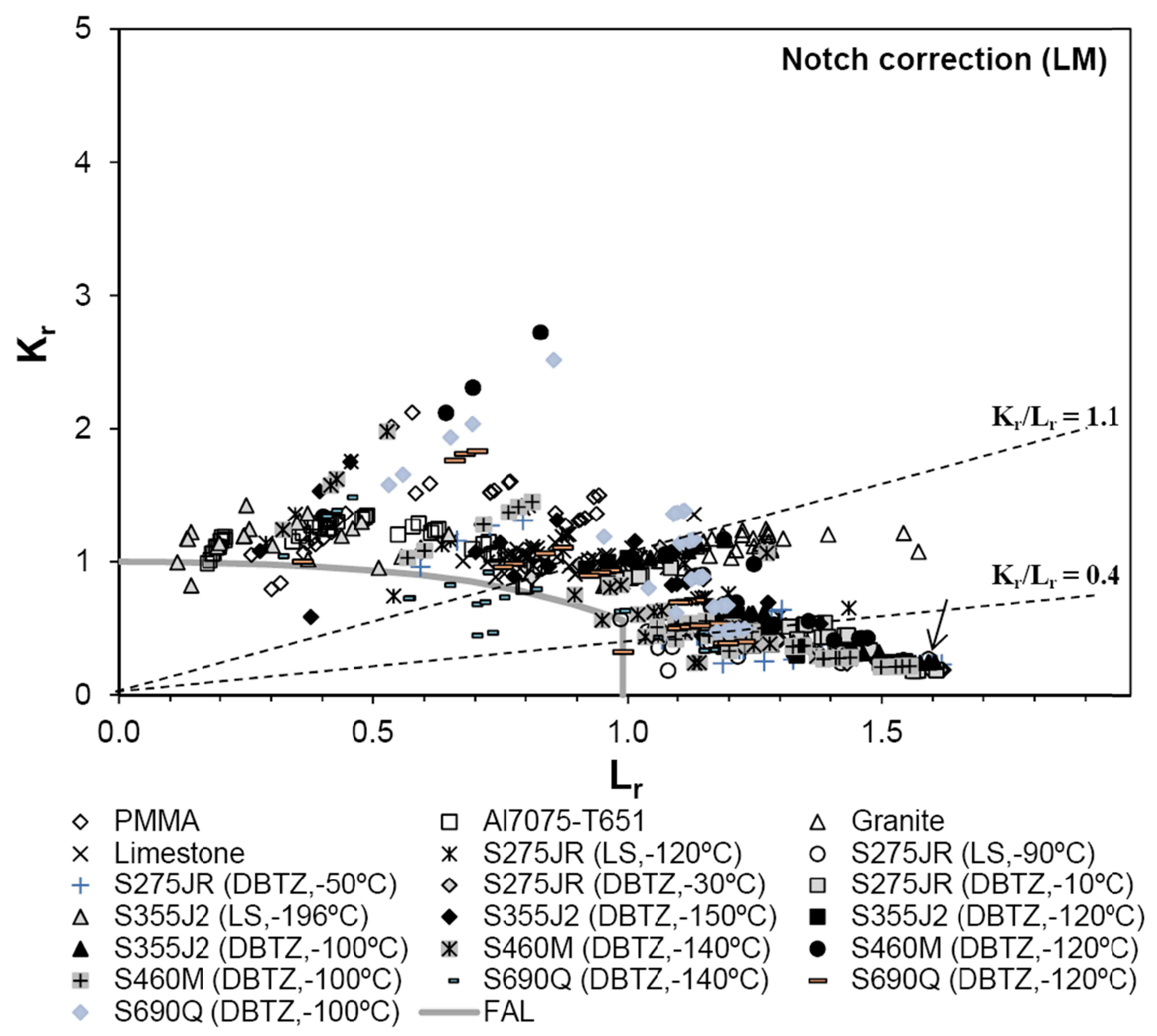

Figure 3. FAD analysis of the 555 experimental results when including the LM notch correction in the $\mathrm{K}_{\mathrm{r}}$ parameter (equation (15)). 


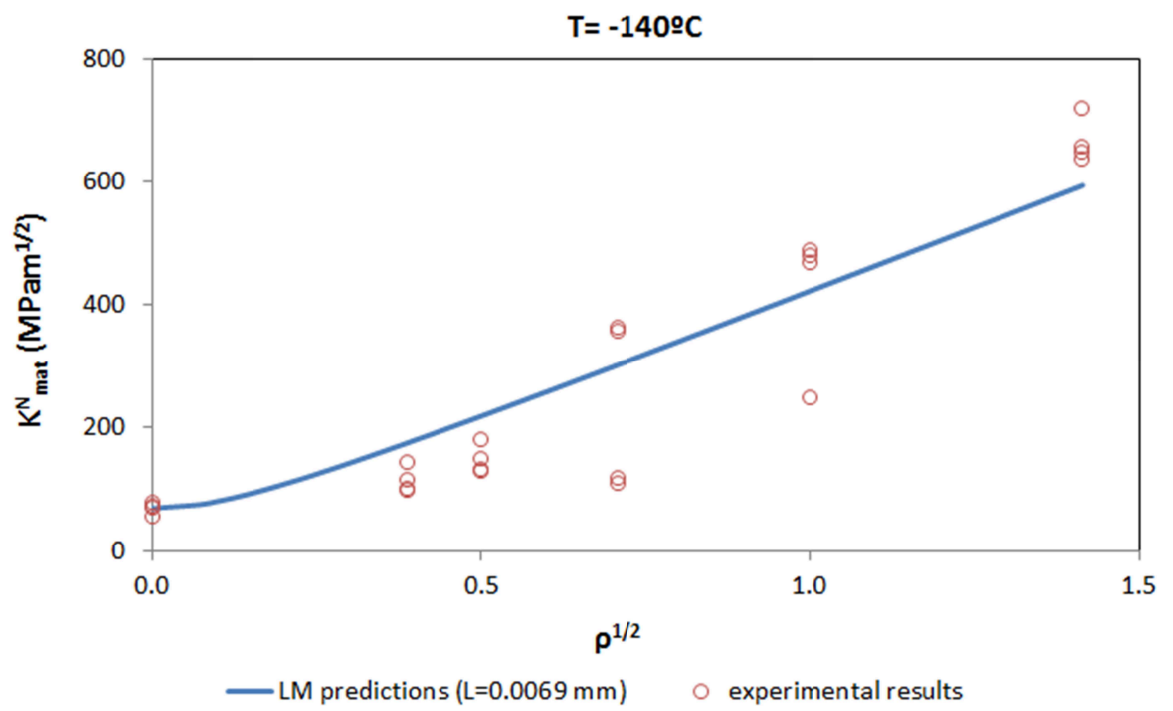

Figure 4. Apparent fracture toughness in steel $\mathrm{S} 690 \mathrm{Q}$ at $-140^{\circ} \mathrm{C}$ : experimental results and LM best fit predictions [10]. 


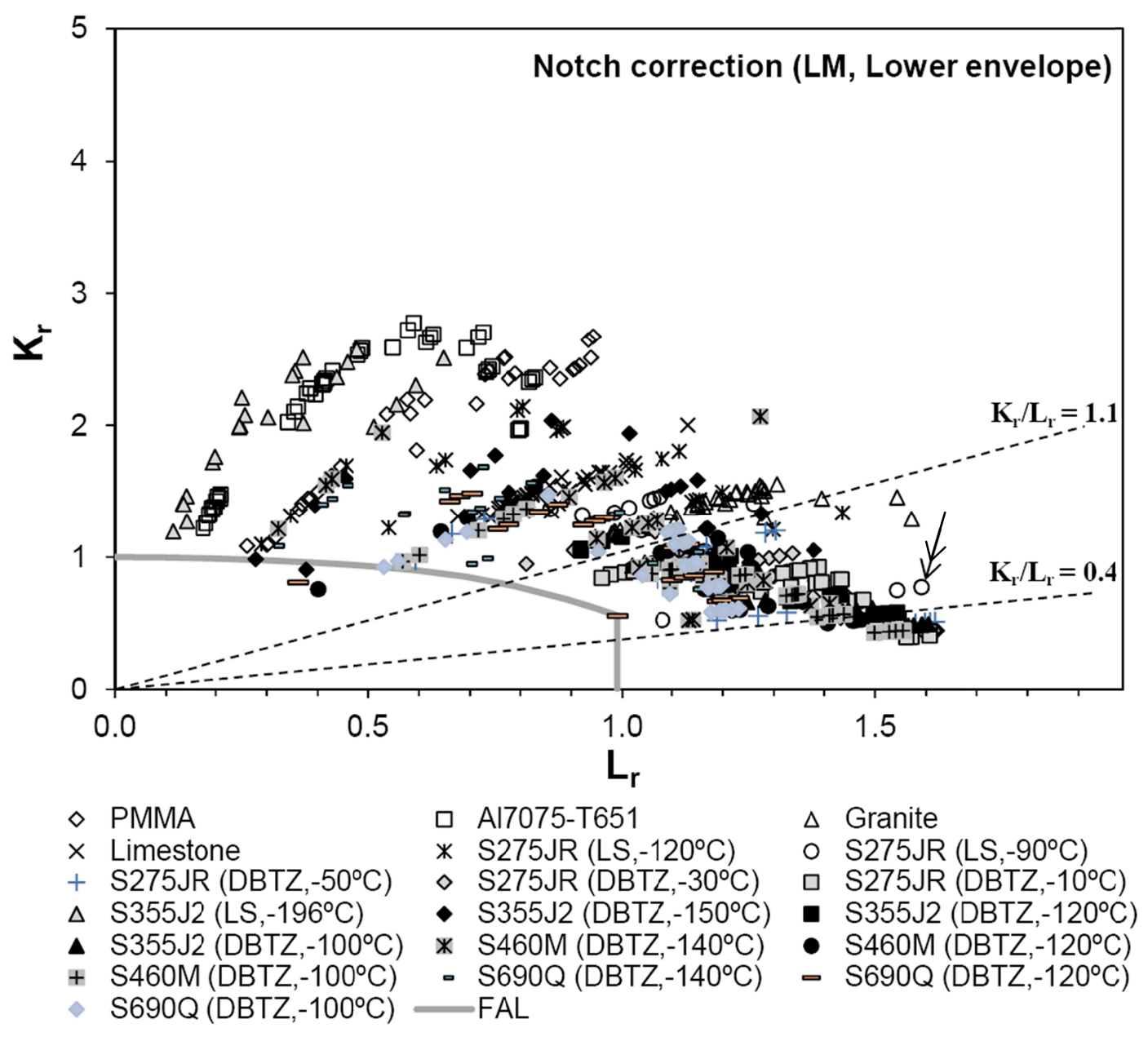

Figure 5. FAD analysis of the 555 experimental results when including the lower envelope of the LM notch correction in the $\mathrm{K}_{\mathrm{r}}$ parameter (equation (17)). 


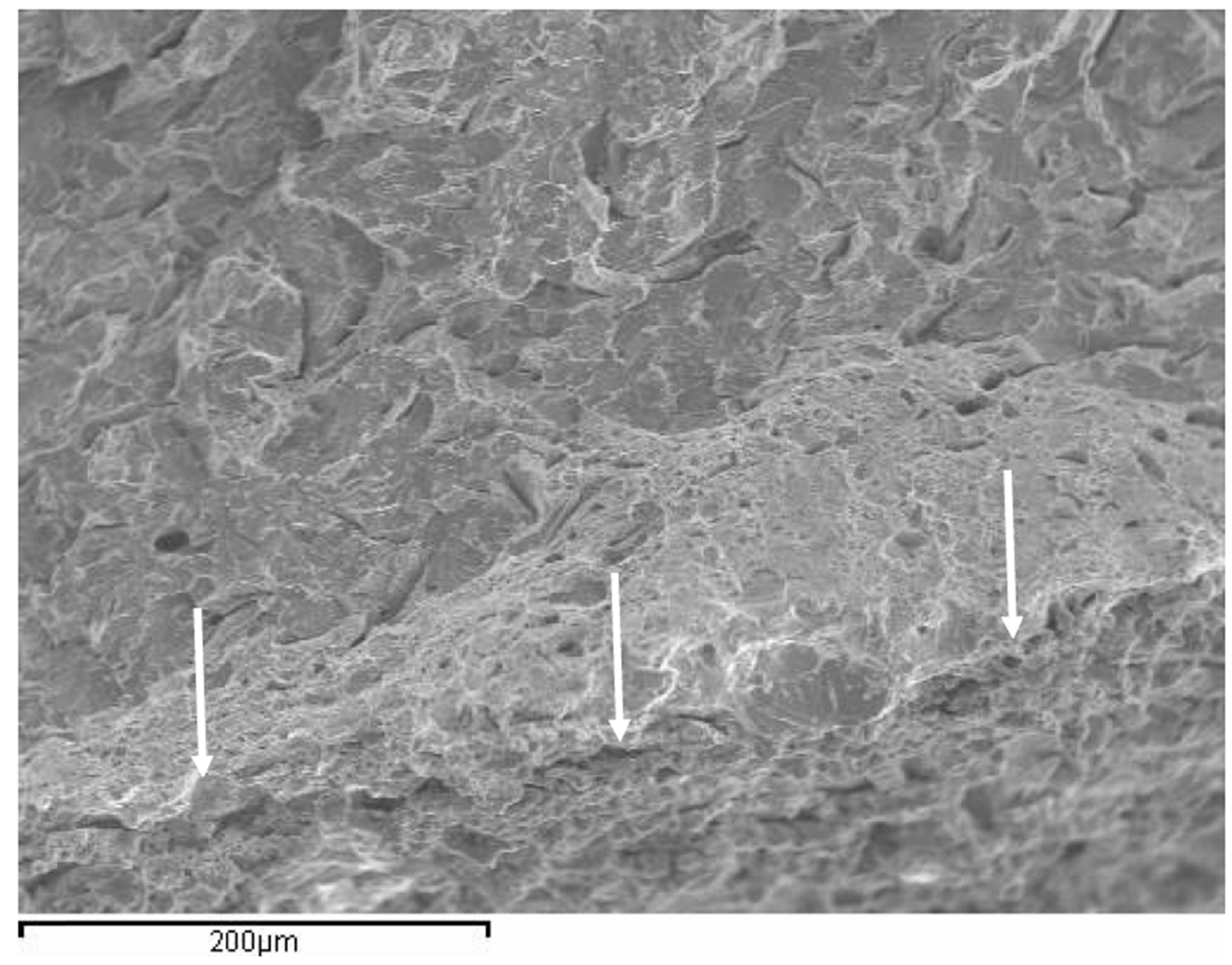

Figure 6. Fracture micromechanisms in steel $\mathrm{S} 275 \mathrm{JR}$ at $-90^{\circ} \mathrm{C}$. Notch radius $=2.0 \mathrm{~mm}$. The arrows indicate the initial defect front. 